\title{
LA LEY GENERAL DE EDUCACIÓN Y LA PROFESIONALIDAD DE UN DOCENTE ${ }^{\alpha}$
}

\section{The General Education Act and the professionalism of a teacher}

\section{José María Rozada Martínez ${ }^{\circledR}$}

La Ley General de Educación (LGE) admite al menos dos niveles de lectura: como normativa que llega a los centros y como hito que señala un cambio importante en el sistema de enseñanza.

En lo que respecta a mi profesionalidad, no fue la misma al principio que con el paso del tiempo. Esta afirmación se basa en un concepto de la profesión que no se deriva del sinnúmero de trabajos realizados en el ámbito de la sociología de las profesiones en general y de la profesionalidad docente en concreto, sino que procede de mi propia experiencia y reflexión autobiográfica. Una concepción que enfatiza el empeño por ubicarse y trabajar en el complejo campo de las relaciones entre el conocimiento académico-universitario, por un lado, y la docencia en las escuelas, los institutos y otras instituciones de enseñanza no universitaria, por otro. El resultado final, tras décadas de andadura en ese viaje a Ítaca, no es un seguro puerto de llegada, sino la convicción de que la identidad más adecuada para situarse y avanzar profesionalmente es la de entenderse a uno mismo como responsable y constructor de su propia pedagogía, que será pequeña por ser biográfica e intransferible, por tanto, no generalizable, además de carente de institución y comunidad de iguales, académico-universitaria o docente, que la acoja y ampare plenamente como algo llevado a cabo por «uno de los suyos». Hablo de algo así como de un tipo de profesional «sin techo»-institucionalmente hablando, claro, aunque dicho con el mayor respeto por quienes padecen socialmente esta lacra-.

\footnotetext{
a Agradezco a Aida Terrón sus comentarios a una primera lectura del texto.

B Camino de Los Tilos, 115, 33429, La Fresneda (Siero, Asturias, España). josemariarozmart@gmail.com.
} 
Con estos mimbres se puede hilvanar un cuadro de doble entrada (Gráfico 1), aunque imperfecto, toda vez que resulta imposible delimitar con precisión cartesiana sus cuatro partes, dadas las múltiples interrelaciones que se dan entre ellas; y tampoco se pueden acotar en el tiempo, porque tanto la LGE como yo tenemos un antes y un después de 1970. Con dicho cuadro a la vista, organizaré esta breve colaboración autobiográfica en cuatro partes.

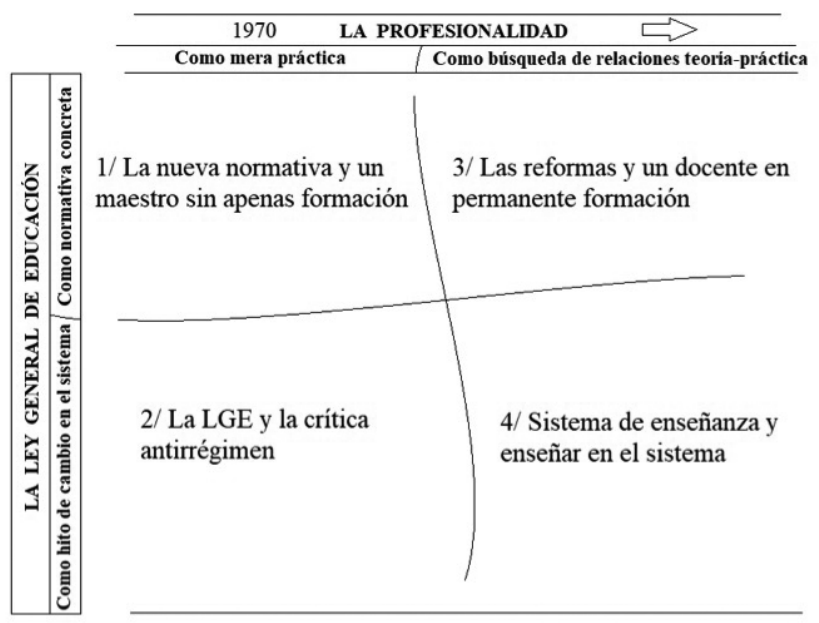

Gráfico 1.

\section{LA NUEVA NORMATIVA Y UN MAESTRO SIN APENAS FORMACIÓN}

En 1970 mi formación era la de un maestro del Plan 1950, sin un bagaje de conocimientos que me permitiera tener la menor posibilidad de intervenir con criterio profesional en una escuela a la que había llegado apenas superada la adolescencia. De las materias que tenía que enseñar sabía poco más que un alumno al terminar el bachillerato elemental; de lo demás, vamos a decir genéricamente, de pedagogía, prácticamente nada. Las metodologías asociadas a las materias que figuraban en el plan de estudios, o no se daban o eran saberes sin relevancia alguna. La Pedagogía, como asignatura específica que se cursaba en los dos últimos años, había consistido en un dictado de apuntes desvitalizado en su contenido y carente de significado alguno para siquiera repensar la experiencia de la escolaridad que teníamos quienes nos 
sentábamos, obligadamente enmudecidos, a tomar unas notas que nos permitieran algo más que una superficial memorización llevada a cabo sin otra motivación que la de aprobar exámenes y «eliminar» materia.

Como bien señalan buen número de estudiosos, cuando se llega a la escuela, máxime si se hace con una formación paupérrima, lo que de inmediato se impone son los modos de hacer que uno mismo ha vivido como estudiante, de modo que la «cultura empírica de la escuela» ${ }^{1}$ se constituye en la base sobre la que el recién llegado dejará algunas pinceladas procedentes de su carácter y otros aspectos de su vida personal.

Hablamos, pues, de una escuela tradicional y un maestro que, sin tener formación suficiente para generar alternativas bien fundadas dentro de ella, se limitaba a introducir pequeños cambios bien intencionados -dictado-copia, partidos de fútbol con los alumnos, televisión para ver programas sobre la naturaleza, proyector de diapositivas, salidas lúdicas o formativas, bromas que distendían el ambiente, algunas preguntas que hicieran pensar y no meramente repetir lo que venía en los libros de texto, etc.- que, gracias al contraste con su desvaído pasado escolar y también a su ignorancia, le proporcionaban una autoestima de innovador.

En los años anteriores y siguientes a la LGE estuve en escuelas unitarias rurales y colegios nacionales. No leí el Libro Blanco ni la propia Ley cuando se publicaron. El primero no establecía norma alguna cuya aplicación me afectara, y, sobre la segunda, ya llegarían las directrices que hubiera que seguir. En las escuelas rurales tal cosa corría a cargo de la inspección, generalmente a través de los «centros de colaboración». En los colegios nacionales eran los directores quienes decían lo que había que hacer y cómo en todo lo referente a las cuestiones administrativas y la organización del centro. De modo que las pautas para cumplimentar adecuadamente los Libros de Escolaridad -anteriores a la

\footnotetext{
1 Agustín Escolano Benito, «Las culturas escolares del siglo XX. Encuentros y desencuentros», Revista de Educación n. ${ }^{\circ}$ ext. (2000): 201-218. Es, a su vez, interesante sobre las culturas escolares, en relación con las reformas e innovaciones educativas, el trabajo de Antonio Viñao Frago, "Culturas escolares, reformas e innovaciones educativas», Con-Ciencia Social 5 (2001): 27-45. También profundizaron, en esta ocasión sobre el «núcleo duro» (ceremonias y mitos) de la cultura escolar, a partir de conceptualizaciones derivadas del materialismo filosófico de Gustavo Bueno, Aida Terrón Bañuelos y Violeta Álvarez Fernández, «Sobre la cultura escolar y los mitos en nuestra escuela», Cultura y Educación 14, no. 3 (2002): 237-252.
} 
propia LGE-, los nuevos ERPAs (Extracto del Registro Personal del Alumno) y cualquier otra documentación con la que los maestros no estuviéramos familiarizados no planteaban mayor problema; siempre resultaba fácil informarse acerca de cómo hacerlo.

Mi LGE fueron las «Nuevas Orientaciones Pedagógicas para la Educación General Básica» publicadas en la revista del CEDODEP (Centro de Documentación y Orientación Didáctica de Enseñanza Primaria). ${ }^{2}$ En ellas estaba todo lo que me hacía falta para orientarme acerca de lo que el Ministerio proponía hacer en la escuela. Nada sabía yo de los fundamentos teóricos de todo aquello. Ni me preocupaban tampoco. Era una propuesta bien ordenada y fácil de consultar; además, se trataba de unas «orientaciones». No dejaba de ser útil consultarlas. Otra cosa era lo que uno fuera a hacer en el aula. Por otra parte, los libros de texto, complementados con sus fichas y el libro del profesor, ya se ocuparían de disponerlo adecuadamente para el trabajo cotidiano con los alumnos. Consultaba dichas orientaciones, aun intuyendo que se trataba de lo que el profesor Viñao denominaría, con atinada chanza, como «uno de esos documentos angelicales, de manual, tan típicos del discurso pedagógico oficial, situado más allá de toda constricción o límite, del bien y del mal, en lugares en los que es difícil hallar referencias a la realidad y a situaciones o circunstancias a tener en cuenta». ${ }^{3}$ A mí me satisfacía leer párrafos en los que se decía, por ejemplo, que se trataba de «unas orientaciones indicativas [o que] los cambios y transformaciones que se introducen en los contenidos, en la metodología y en las actitudes, no son normas que deban seguirse imperativamente, sino que son más bien directrices y sugerencias» ${ }^{4}$ porque me abrían puertas para entrar y salir en lo dispuesto según me pareciera, teniendo siempre una primera línea de defensa si acaso la inspección se presentaba y formulaba alguna objeción con respecto a lo que hacía en mis clases frente a lo que la Ley determinaba. Cosa que, por otra parte, nunca ocurrió, porque tal como dice mi amigo Julio Mateos, también maestro rural entonces: «En no muchas ocasiones visitó mis escuelas la inspección y en esas visitas se

\footnotetext{
2 Vida Escolar, 124-126 (1970-1971).

3 Antonio Viñao Frago, «La Educación General Básica. Entre la realidad y el mito», Revista de Educación n. ${ }^{\circ}$ ext. «La Ley General de Educación veinte años después» (1992): 59.

4 Vida Escolar, 124-126 (1970-1971): 11.
} 
limitaba a una conversación distendida conmigo». ${ }^{5}$ No conocí una inspección fiscalizadora de programaciones tecnicistas, como suele decirse cuando se resalta, creo que en exceso, lo que supuso en la escuela la llegada de la idea de que había que programar pormenorizadamente la actividad escolar. Estando en una escuela rural, vino a verme la inspectora y en el informe que redactó escribió lo siguiente: «Hemos podido advertir el buen deseo del Sr. Rozada de adaptar las exigencias educativas y didácticas a los distintos niveles de los alumnos: de edad, situación de escolaridad, ambiental [...] con un intento de programación aceptable. [Los subrayados son míos, JMR]».6 Sin embargo, he de decir que mi programación no seguía taxonomía alguna; consistía en unas hojas de tamaño DinA4 divididas en tantas columnas como días tiene la semana, anotando muy esquemáticamente en cada una de ellas lo que iba a trabajar con cada pequeño grupo en los que estaban divididos los alumnos de aquella escuelita rural; no había objetivos generales ni específicos ni operativos ni verbos de acción para formularlos; se trataba de algo mucho más sencillo, que hacía para evitar la ansiedad que produce el tener que pensar sobre la marcha lo que a cada cual se le va a proponer, pero sin la pretensión de establecer con rigidez lo que la gestión de la vida del aula aconsejara hacer en cada momento.

Contra esa idea tan extendida de que la LGE trajo consigo una insoportable presión tecnicista sobre el trabajo del docente, añadiré solamente una anécdota que refleja bien el perfil de algunos inspectores en aquella época. En otra de mis escuelas, como me gustaba tener a la vista lo que íbamos a hacer a lo largo del día, porque era una buena manera de que también los alumnos se ubicaran en el tiempo y sobre el tipo de materia que íbamos a abordar durante la primera hora, después del recreo y por la tarde, cogí el cuadro de una Inmaculada de Murillo que a mi llegada estaba colgado en la pared del fondo de la clase, le di la vuelta y, aprovechando el marco, coloqué con orgullo de innovador un

\footnotetext{
5 Julio Mateos Montero, Materia y fantasías pedagógicas (sin paginar) (https://www.materiayfantasiapedagogicas.es/memoria-profesional/) (consultada el 20-2-2021).

Quiero aprovechar esta nota para agradecerle a Pedro Antonio Carrio Martínez, compañero de estudios, amigo y también maestro rural a finales de los años sesenta y comienzos de los setenta, la larga conversación que mantuvimos el martes 9 de febrero del 2021, ayudándome a recordar numerosos aspectos sobre los que mi memoria mostraba inseguridad.
}

6 Enseñar, y pensar la profesión. Autobiografía de un docente. Autoedición (2018), 130 (http://www. formarsecomoprofesor.es/autobiografia/). 
cuadro horario bien visible. Cuando llegó la inspectora, preguntó por la Virgen.

Puedo afirmar que en las aulas donde enseñé, el tecnicismo no irrumpió agresivamente impulsado por la inspección. Al menos en algunos casos, el pasado se mantuvo como amortiguador de la llegada de lo nuevo. Yo mismo, a pesar de los diagramas de Venn, los subconjuntos, las intersecciones, los fonemas, los morfemas, los lexemas y otros contenidos que también eran nuevos para mí, sin dejarlos de lado, seguí dedicándole el tiempo que hiciera falta a la lectura, la escritura y el cálculo, que me parecían -y me siguen pareciendo hoy- saberes «instrumentales» básicos. Las Orientaciones Pedagógicas las consultaba, por ejemplo, para medir la velocidad lectora de cada uno de mis alumnos, haciéndome así una idea de lo lejos o cerca que estaban de los estándares que los expertos señalaban como orientativos, o el conocimiento del Sistema Métrico Decimal que correspondía a las distintas edades y niveles del alumnado, lo que me orientaba mucho acerca de con qué alumnos debería insistir más sobre determinados contenidos.

El cómo se lleva un aula o una escuela fue, al menos en mi caso, escasamente alterado por la LGE, y no por el criterio bien fundado que tuviera contra ella para pararle los pies en algo, sino porque la recibí desde una cultura escolar asentada y la personalidad de un docente determinado, únicamente dispuesto a cambiar aquello que le viniera bien a su manera de entender y hacer las cosas; y porque tampoco, como he dicho, la propia Ley y sus desarrollos normativos pretendieron entrar en el aula imperativamente, toda vez que los agentes mediadores entre la administración y los centros, al menos los que yo he conocido, en unos casos pertenecían a un mundo en declive y en otros fueron, discreta y un tanto paternalistamente, bastante respetuosos con los maestros y nuestras formas de enseñar.

\section{LA LGE Y LA CRÍTICA ANTIRRÉGIMEN}

Se ha dicho muchas veces que la LGE tiene su origen político e ideológico en lo que hoy denominamos «tardofranquismo». Mi capacidad crítica con respecto a ella también surge en dicho contexto. Tras venir con quince años del pueblo a la ciudad para pasar tres cursos en la despolitizada y anodina Escuela Normal -las únicas discusiones que 
recuerdo eran las que se producían los lunes a propósito de los resultados de la liga de fútbol-, mis avances en la percepción del régimen político en que vivía se iniciaron básicamente en los pisos que compartí con estudiantes -finales de los años sesenta-, algunos de ellos universitarios, así como en el denominado "movimiento de interinos»-comienzos y mediados de los años setenta-, que en 1974 cristalizó en la Asociación de Antiguos Alumnos de Magisterio de Oviedo, cuyo artesanal Boletín ciclostilado documenta bastante bien el enfoque y el contenido de las críticas que entonces le hacíamos a la LGE los maestros asturianos más movilizados. Mi encuentro con la LGE no se dio, pues, solamente en los lugares de trabajo, sino también en el contexto del activismo presindical y político. La lectura de los ejemplares del mencionado Boletín permite acercase al tipo de recepción que la Ley tuvo en aquel ambiente reivindicativo y contestatario. No es aventurado decir que a dicha Ley «se la juramos» no tanto por el análisis interno e histórico que hiciéramos de ella, sino por ser criatura procedente del régimen que combatíamos procurando erosionarlo cuanto pudiéramos, resultando que unas veces criticábamos la Ley por lo que establecía y otras porque no se cumplía. No fui particularmente beligerante contra ella, pero, en general, me parecían bien todas las críticas, no por su nivel de argumentación, sino por ir contra quien iban.

Por ejemplo, criticábamos, entre otras muchas cosas, el efecto segregador que tenía la Ley en sí: «la Ley de Educación está montada para seleccionar a una minoría que acceda a estudios superiores, mientras la mayoría pasa a la Formación Profesional (si encuentran dónde) como futura mano de obra abundante» $;^{7}$ pero protestábamos también contra su deficiente aplicación señalando, por ejemplo, que las tasas de escolarización en preescolar no llegaran al 50\% en España ni superasen el $20 \%$ en Asturias, o por las precarias condiciones en las que eran escolarizados muchas veces los alumnos: «En Oviedo y en algunos otros lugares de la provincia, [...] ha habido que recurrir a las aulas prefabricadas». 8 Por cierto, que yo mismo enseñé en alguno de aquellos barracones, incluso en locales prestados, como el de una dependencia

\footnotetext{
7 Boletín de la Asociación de AA. AA. de la Escuela Universitaria de formación del Profesorado de EGB (mayo 1975): 8. En la mayoría de las colaboraciones no figura el autor. Su confección era tan artesanal y descuidada que no hacíamos constar el número, incluso no se conservaba la cabecera.
}

8 Boletín de la Asociación de AA. AA. de la Escuela Universitaria de EGB (noviembre 1975): 22. 
parroquial anexa a la iglesia del pueblo. Sin embargo, he de reconocer que al mismo tiempo que criticaba las pésimas condiciones de escolarización, personalmente, al menos en parte, las disfrutaba, porque estar alejado del edificio principal del colegio me permitía esa mayor libertad que es propia de las escuelas rurales. Así que sobre este aspecto no fui beligerante sobre el terreno, pero sí sobre el papel, en las asambleas y donde quiera que se tratara de argumentar contra un régimen político execrable.

\section{LAS REFORMAS Y UN DOCENTE EN PERMANENTE FORMACIÓN}

Atendiendo a la idea de profesionalidad que presento en el segundo párrafo de este texto, a finales de los setenta mi vida profesional comenzó a recorrer el camino que en él se señala. Cuando, tras finalizar la Licenciatura en Filosofía y Letras, y, por encargo del director del Departamento de Geografía, comencé a interesarme por la enseñanza de dicha materia, empecé a descubrir el inmenso valor formativo que tenían la denominadas Ciencias de la Educación para repensar mi profesión. Pero no como ejercicio académico, sino modestamente y a la vez sin miedo, releyéndolas también a ellas con el fin de acercar en la mente y en la práctica de un maestro concreto los mundos separados del conocimiento académico y de los quehaceres de la escuela.

A partir de ahí, en un proceso lento que duraría ya toda mi vida profesional, fui manejando saberes sobre las disciplinas que enseñaba, los modelos didácticos, la teorías de la educación y del currículum, las principales aportaciones de las psicologías del desarrollo y del aprendizaje, la sociología de la educación, la antropología, la historia de la educación -sobre esta he de reconocer aquí que de manera un tanto tardía- y cuanto me viniera bien para pensar mi profesión, pero, como digo, no de una manera académicamente enciclopédica, lo que, por otra parte, me habría resultado imposible, sino a la búsqueda de ideas que me inspiraran formas de enseñar, no ideales, sino posibles, diseñadas biográficamente como el pensamiento y la acción de un docente determinado.

Ese camino atravesó numerosas reformas. En lo que respecta a la LGE he decir que obtuve gran beneficio profesional de la creación en su día del Ciclo Superior de la EGB, del que luego fui convencido 
defensor, ${ }^{9}$ porque, entre los años 1982 y 1987 tuve la oportunidad y la dicha de enseñar Ciencias Sociales en sexto, séptimo y octavo cursos, llevando mi profesionalidad al nivel más gratificante que ha alcanzado, al crear un método adecuado a mis ideas y posibilidades de acción, que no fueron pocas, porque, como he dicho -tomando distancia de la muy extendida cultura de la queja-, las puertas para entrar y salir en las disposiciones administrativas son muy amplias en el nivel de la docencia concreta. En mi caso, revisaba el programa de Ciencias Sociales hasta dejarlo en seis u ocho temas por curso; no examinaba ni formulaba objetivos, sino unas intenciones muy generales que me ayudaban a seleccionar los contenidos más acordes con ellas, además de seguir una secuencia de actividades bien fundamentada; todo con un respaldo argumental basado en algunas de las multidisciplinares lecturas que hacía. Para entonces ya comenzaba a estar profesionalmente empoderado para someter a crítica las propuestas didácticas de raigambre tecnicista, vinieran de donde viniesen, valdría decir, porque las reformas siguientes no variarían en esto el rumbo señalado por la LGE. ${ }^{10}$ También es cierto que continué gozando de la libertad para organizar mi docencia que había tenido en 1970, si bien ahora podía explicar con «cierta» solvencia pedagógica lo que hacía. ${ }^{11}$

\section{SISTEMA DE ENSEÑANZA Y ENSEÑAR EN EL SISTEMA}

Es comúnmente aceptado que los grandes hitos que marcan el devenir histórico del sistema de enseñanza en España son la Ley Moyano (1857) y la Ley General de Educación (1970). Eso lo aprendí a comienzos

\footnotetext{
9 «En defensa de la Escuela Pública y contra el dogmatismo de que los niños y las niñas de 12-14 años deban abandonar las escuelas y escolarizarse necesariamente en los institutos». Con-Ciencia Social 2 (1998): 226-231.

10 «Las reformas y lo que está pasando. (De cómo en la educación la democracia encontró su pareja: el mercado)», Con-Ciencia Social 6 (2002): 15-57. (http://www.formarsecomoprofesor.es/category/2002/las-reformas-y-lo-que-esta-pasando-de-como-en-la-educacion-la-democracia-encontrosu-pareja-el-mercado/).

11 Aunque, sin duda, el lector entenderá el adjetivo «cierta» en su acepción de «pequeña cantidad», debo decir que en lo referido al establecimiento de relaciones entre el conocimiento académico sobre la educación y la práctica docente, lo pequeño no es poco, teniendo en cuenta que no forma parte de ninguna de las tres culturas escolares (la empírica de los enseñantes, la científica de los académicos y la política de los gestores, tal como las denomina el profesor Escolano) la idea de que un docente explique con fundamentos teóricos solventes los porqués de lo que hace en la escuela. Hablo de eso que al final de mi vida profesional he rotulado como "pequeña pedagogía» (http://www.formarsecomoprofesor.es/mi-pequena-pedagogia/).
} 
de los ochenta, que fue cuando leí a Puelles Benítez, ${ }^{12}$ a Carlos Lerena ${ }^{13}$ y a otros a partir de ellos, lo cual tuvo dos efectos: el primero, el de superar la crítica que venía haciendo a la LGE a lo largo de la década anterior, elevándola del nivel de normativa surgida de un régimen político detestable, al de un sistema que está por encima incluso de la muerte de un dictador y la construcción de una democracia; el segundo, el de asumir el reto de encontrarle sentido a una enseñanza que se lleva a cabo y se piensa en el seno de un sistema cuyas funciones últimas se cumplen independientemente de lo que piensen y hagan quienes trabajan en él.

La sociología parecía menospreciar el trabajo didáctico que había comenzado a desarrollar, no solo con el fin inmediato de mejorar mis clases, sino también de comprender mejor los problemas que tenía entre manos y el contexto en que debía abordarlos. Por ejemplo, golpeaba mi cabeza por dentro, amenazando con paralizar mi trabajo, la sentencia de mi admirado Carlos Lerena: "No son los maestros quienes fundamentalmente hacen la escuela, sino la escuela la que hace a los maestros». ${ }^{14}$ Si leía psicología con el fin de saber algo acerca de los procesos de desarrollo y de aprendizaje, me enfrentaba a la crítica de estar psicologizando problemáticas que son políticas y sociales. Si leía teoría del currículum para organizar mínimamente un método, tenía que hacerme cargo de la advertencia acerca de si no estaría pretendiendo elevar mi estatus profesional reduciendo a un problema técnico lo que era un asunto político. Nunca había sido taylorista, entre otras cosas porque ni la LGE ni cuantas la sucedieron me habían obligado a ello, pero resultaba que ahora podía estar incurriendo en neotaylorismo:

A cambio de su conversión a estos programas destinados a otorgarles el título de profesionales competentes, los poderes públicos parecen ofrecerles el estatuto de técnicos de la enseñanza frente al de misioneros laicos. El profesor «neotaylorizado» entra así en una espiral de contradicciones sin fin, al tener

\footnotetext{
12 Manuel de Puelles Benítez, Educación e ideología en la España contemporánea (1767-1975) (Barcelona: Labor,1980).

13 Carlos Lerena Alesón, Escuela, ideología y clases sociales en España. Crítica de la sociología empirista de la educación (Barcelona, Ariel, 1980).

14 Carlos Lerena Alesón, «El oficio de maestro. La posición y el papel del profesorado de primera enseñanza en España», Sistema 50-51 (1982): 92.
} 
que encontrar salidas técnicas a cuestiones que no son ni principal ni exclusivamente técnicas sino políticas. ${ }^{15}$

«Pensar alto y actuar bajo», decían mis amigos del Grupo Nebraska y de la Federación Icaria, ${ }^{16}$ que también estudiaban en casa y enseñaban en el aula. Yo, que no estudiaba tanto como ellos porque cuando algo me convencía, en lugar de seguir avanzando en el conocimiento académico acerca del tema, me empeñaba en ponerlo en relación con el día a día del aula, lo cual me alejaba de la idea de convertir en asunto principal de mi profesión la crítica de un sistema que, en cualquier caso, seguiría fuera del alcance de mi actividad como docente. Ya en los años noventa asistí a innumerables y largas sesiones muy críticas con el neoliberalismo y el sistema de enseñanza, en el marco de la Plataforma Asturiana de Educación Crítica que pusimos en marcha un numeroso grupo de docentes asturianos; sin embargo, al llegar a casa me ponía con ilusión a trabajar en mi "pequeña pedagogía» ${ }^{17}$.

A mi modo de ver, constituye un error descuidar la atención a la profesionalidad docente apelando al hecho de que sigan ahí las inevitables funciones estructurales del sistema educativo, aunque solo sea porque dicha profesionalidad, si está adecuadamente enfocada, es decir, si adopta un enfoque crítico que incluya la atención a la teoría y a la práctica en un sentido dialéctico y amplio, y no como mero y siempre frustrado intento de aplicación técnica de un conocimiento científico, entonces el docente no es un mero didacta que restringe su mirada profesional al aula, sino que atiende también a lo que se dice sobre el sistema en que trabaja. El conocimiento de sus funciones estructurales, en las que la LGE constituye una baliza para señalar la transición entre el «modo de educación tradicional-elitista» y el «modo de educación tecnocrático de masas», ${ }^{18}$ supone una importante fuente de ideas para pensar la profesión más allá de cualquier didactismo ingenuo.

\footnotetext{
15 Julia Varela, «The marketing of education: neotaylorismo y educación», Educación y Sociedad 1 (Madrid Akal, 1983): 176.

16 Sobre la Federación Icaria, ver www.fedicaria.org.

17 «La formación permanente del profesorado y el desarrollo de una "pequeña pedagogía" crítica. Notas autobiográficas de una vida profesional en la frontera», en La formación del profesorado y la mejora de la educación. Políticas y prácticas, eds. Juan Manuel Escudero Muñoz y Alberto Luis Gómez (Barcelona: Octaedro, 2006), 197-229. (http://www.formarsecomoprofesor.es/mi-pequena-pedagogia/).

18 Raimundo Cuesta Fernández, Sociogénesis de una disciplina escolar: la Historia (Barcelona, Pomares-Corredor, 1997), 20.
} 


\section{REFERENCIAS}

Cuesta Fernández, Raimundo. Sociogénesis de una disciplina escolar: la Historia. Barcelona, Pomares- Corredor, 1997.

Escolano Benito, Agustín. "Las culturas escolares del siglo XX. Encuentros y desencuentros», Revista de Educación n. ${ }^{\circ}$ ext. (2000): 201-218.

Lerena Alesón, Carlos. Escuela, ideología y clases sociales en España. Crítica de la sociología empirista de la educación. Barcelona, Ariel, 1980.

Lerena Alesón, Carlos. «El oficio de maestro. La posición y el papel del profesorado de primera enseñanza en España», Sistema 50-51 (1982): 79-102.

Puelles Benítez, Manuel de. Educación e ideología en la España contemporánea (1767-1975). Barcelona: Labor,1980.

Rozada Martínez, José María. «En defensa de la Escuela Pública y contra el dogmatismo de que los niños y las niñas de 12-14 años deban abandonar las escuelas y escolarizarse necesariamente en los institutos», Con-Ciencia Social 2 (1998): 226-231.

Rozada Martínez, José María. «Las reformas y lo que está pasando. (De cómo en la educación la democracia encontró su pareja: el mercado)», Con-Ciencia Social 6 (2002): 15-57.

Rozada Martínez, José María. «La formación permanente del profesorado y el desarrollo de una "pequeña pedagogía" crítica. Notas autobiográficas de una vida profesional en la frontera», en La formación del profesorado y la mejora de la educación. Políticas y prácticas, eds. Juan Manuel Escudero Muñoz y Alberto Luis Gómez, 197-229. Barcelona: Octaedro, 2006.

Rozada Martínez, José María. Enseñar, y pensar la profesión. Autobiografía de un docente. Autoedición (2018), 130 (http://www.formarsecomoprofesor.es/ autobiografia/).

Terrón Bañuelos, Aida y Violeta Álvarez Fernández, «Sobre la cultura escolar y los mitos en nuestra escuela», Cultura y Educación 14, no. 3 (2002): 237252.

Varela, Julia «The marketing of education: neotaylorismo y educación». Educación y Sociedad 1 (1983): 167-177.

Viñao Frago, Antonio. «La Educación General Básica. Entre la realidad y el mito», Revista de Educación n. ${ }^{\circ}$ ext. "La Ley General de Educación veinte años después» (1992): 47-71.

Viñao Frago, Antonio, "Culturas escolares, reformas e innovaciones educativas», Con-Ciencia Social, 5 (2001): 27-45. 